\title{
Subungual superficial angiomyxoma
}

\author{
Kristian G Malpass BSc MD ${ }^{1}$, Charles FT Snelling MD FRCSC ${ }^{1}$, \\ Martin J Trotter MD PhD FRCSP2
}

KG Malpass, CFT Snelling, MJ Trotter. Subungual superficial angiomyxoma. Can J Plast Surg 2002;10(2):85-88.

This is the first report of a subungual superficial angiomyxoma. Excision followed 12 months of lesion growth and progressive index nail-plate elevation. The encapsulated mass was separated bluntly from the nail bed undersurface, although sharp dissection was required to split the periosteal interface. Five cases of subungual myxoma have been reported. Histologically, both superficial angiomyxoma and myxoma entities contain spindle and stellate cells within a myxoid stroma. Vascular and cellular elements found only in superficial angiomyxoma were identified in the featured lesion. Recurrence rates following superficial angiomyxoma excision are greater than those of myxoma. This patient did not experience recurrence after 11 postoperative months.

Key Words: Angiomyxoma; Fingernail; Myxoma; Nailbed; Subungual

\section{L'angiomyxome sous-unguéal superficiel}

RÉSUMÉ : Il s'agit du premier compte rendu d'angiomyxome sous?unguéal superficiel. L'excision a fait suite à une croissance de la lésion accompagnée d'une élévation progressive de la table unguéale de l'index sur une période de 12 mois. La masse encapsulée a été carrément séparée du lit inférieur de l'ongle, mais une dissection méticuleuse s'est révélée nécessaire pour séparer l'interface périostique. Cinq cas de myxome sous-unguéal ont été déclarés. Du point de vue histologique, tant l'angiomyxome superficiel que les myxomes contenaient des cellules fusiformes et étoilées dans un stroma myxomateux. Des éléments vasculaires et cellulaires observés seulement dans l'angiomyxome superficiel ont été repérés dans la lésion en question. Le taux de récurrence suivant l'excision d'un angiomyxome superficiel est plus élevé que dans le cas des myxomes. Ce patient n'avait pas présenté de récurrence onze mois après l'opération.
$\mathrm{V}$ irchow (1) introduced the term 'myxoma' in 1863 to describe a soft tissue lesion resembling fetal umbilical tissue. Stout (2) offered a detailed description of a myxoma in 1948, including common histological features that were observed in several cases. A myxoma presenting in the subungual region of the hand was first recognized and its treatment was described by Sanusi (3) in 1982. Allen et al (4) were the first to differentiate superficial angiomyxoma from myxoma based on a prominent vascular pattern and increased cellular density. The present case report describes a lesion resected from beneath a fingernail bed that demonstrated the histolog- ical characteristics of superficial angiomyxoma, a lesion hitherto not described in this anatomical position.

\section{CASE PRESENTATION}

A 30-year-old man presented with gradual clubbing of his left index fingernail (Figure 1). The patient noticed the deformity 12 months before presenting to the physician. Finger discomfort was not an issue and the deformity never interfered with the patient's typing-intensive occupation. The patient did recall that the finger was slammed in a car door 23 years before the lesion first appeared.

${ }^{1}$ Division of Plastic Surgery and ${ }^{2}$ Department of Pathology, University of British Columbia, Vancouver Hospital and Health Sciences Centre, Vancouver, British Columbia

Correspondence and reprints: Dr CFT Snelling, 306-888 8th Avenue, Vancouver, British Columbia V5Z 3Y1. Telephone 604-873-9333, fax 604-874-6717, e-mail snelling@interchange.ubc.ca 


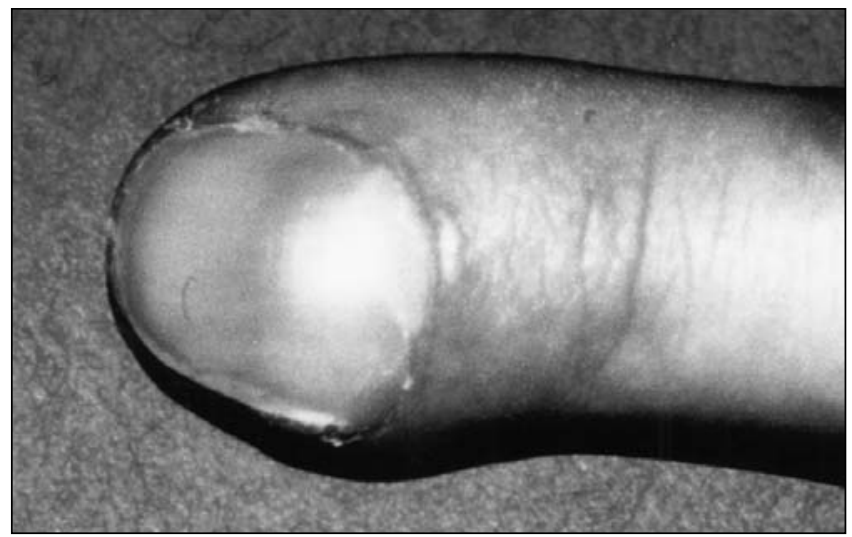

Figure 1) Preoperative dorsal view of the index finger illustrating deformation of the index nail plate with elevation of the ulnar border of the index nail plate border dorsal to the lateral nail fold
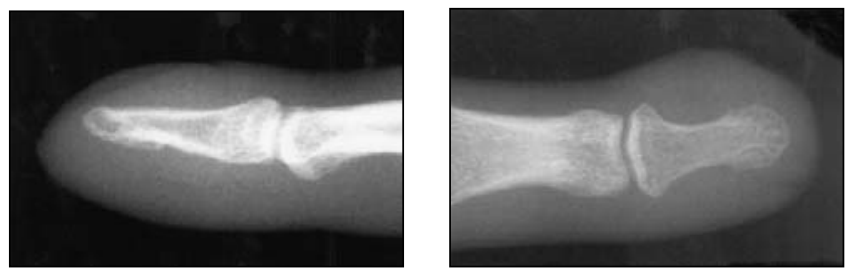

Figure 2) Left Lateral radiograph depicting a soft tissue mass nail plate elevation without bony erosion. Right Anteroposterior radiograph showing soft tissue bulging at ulnar border. Distal phalanx shows no bony erosion

Physical examination revealed deformation of the distal phalanx that spared the distal interphalangeal joint. The digit did not appear erythematous, nor was it draining. The lesion had raised the intact nail plate above the lateral nail fold, exposing a strip of desiccated nail bed that was $2 \mathrm{~mm}$ wide and was the length of the visible nail plate. Palpation caused mild discomfort and demonstrated nonfluctuant swelling. The joint was not tender. Nail bed capillary refill and static two-point discrimination were normal. Active and passive range of motion at the distal interphalangeal joint was intact. Radiographs suggested soft tissue swelling dorsal to the distal phalanx that elevated the base of the nail plate (Figure 2, left). Bony erosion was not a feature (Figure 2).

The mass was removed two months after the initial presentation, during an outpatient procedure. Following ring block anesthesia, a bloodless field was achieved with a penrose drain-tourniquet wrapped around the base of the finger. The proximal nail fold was elevated from the nail plate as a proximal-radial based flap. The volar surface of the nail plate was separated bluntly from the underlying nail bed and germinal matrix. A longitudinal incision $2 \mathrm{~mm}$ from the ulnar nail fold was made through the nail bed and down to bone, and the desiccated strip of nail bed was removed. The remaining nail bed was dissected bluntly from the lesion to reveal an encapsulated discrete mass. Sharp dissection was required to break down fine adhesive bands that anchored the lesion to the dorsal periosteal surface of the distal phalanx.
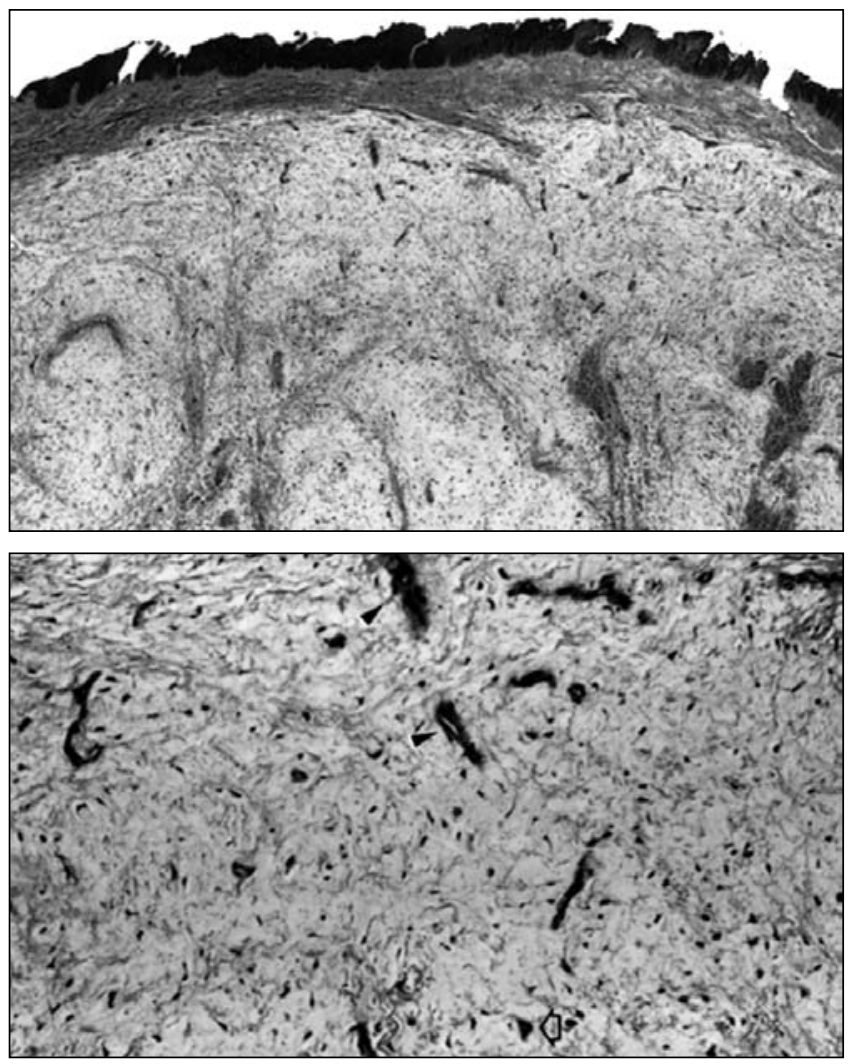

Figure 3) Top Low power photomicrograph of superficial angiomyxoma underlying the nail bed epithelium. Hematoxylin and eosin (original magnification $\times 30$ ). Bottom The tumour demonstrates a loose myxoid matrix with scattered fibroblast-like cells, some with a stellate appearance (hollow arrow). Numerous small vessels are also present within the lesion (black triangle). Hematoxylin and eosin (original magnification $\times 125$ )

Grossly, the lesion was light beige, oval shaped, and encapsulated discretely as a $1.1 \times 1.0 \times 0.9 \mathrm{~cm}$ mass. Histologically, the specimen was a well-circumscribed dermal lesion consisting of spindle shaped and stellate cells on a background of myxoid stroma. A prominent vascular component and significant cellularity led to a diagnosis of superficial angiomyxoma (Figure 3). No epithelial structures or elements were noted.

Following removal of the lesion, the nail bed was replaced against the bone by inserting the nail plate between the dorsal roof of the nail fold and the germinal matrix. A proximal docking stitch, centered at the base of the nail plate, was used to guide the nail within the proximal nail fold (Figure 4). Simple sutures were placed to anchor the nail plate below the radial and ulnar nail folds.

The patient returned to typing two months after surgery and, at the 11-month follow-up visit, was playing guitar without difficulty. There was no evidence of tumour recurrence at 46 weeks and a smooth nail regrew with a reduced curvature. A short scar extended proximally from the ulnar nail base to the flap margin (Figure 5).

\section{DISCUSSION}

Allen et al (4) reported the superficial angiomyxoma in 1988 as a lesion distinct from myxoma, based on the pres- 


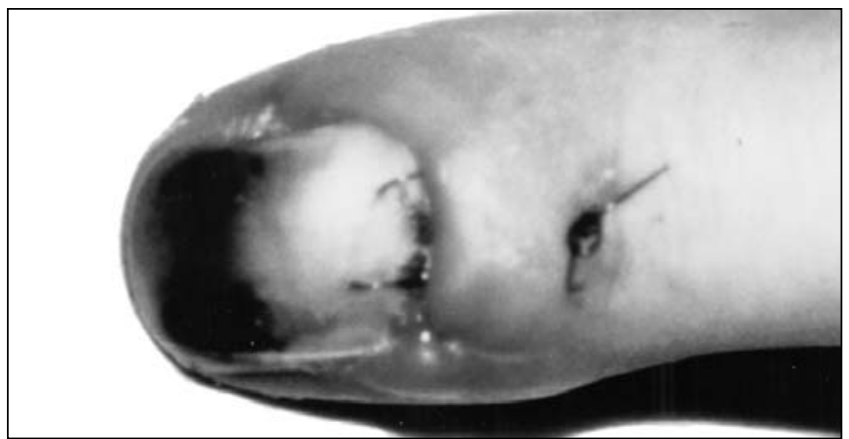

Figure 4) Dorsal postoperative view with docking stitch securing the nail plate below the proximal nail fold. The proximal nail fold incision used to approach the ulnar margin of nail matrix is visible

ence of collagenous septae, thin-walled blood vessels and a moderate inflammatory infiltrate within the common mucoid surroundings. Both Allen et al (4) and Calonje et al (5) identified superficial angiomyxoma as a dermal subcutaneous lesion. In contrast, Stout (2) reported 25 subcutaneous myxomas -10 in bone and four in skin. Ireland et al (6) and Enzinger (7) reported 66\% (38 of 58) and 100\% (34 of 34) of observed myxomas in the intramuscular position, respectively. Combining the Stout (2), Ireland et al (6) and Enzinger (7) series, 18\% (26 of 147) of reported myxomas were located in the upper limbs, only 5\% (seven of 147) were found in the hand, and no myxomas were found in the subungual region. Alternatively, only 6\% (four of 69) of superficial angiomyxomas were reported in the upper limbs, none of which were described in the hand $(4,5)$. Sanusi (3) reported the first subungual myxoma in 1982.

A cylindrical or clubbed nail deformity was the primary reason for presentation in each of five patients with subungual myxomas reported to date $(3,8-11)$. Pain was an additional concern for two patients $(9,10)$, while susceptibility to subungual hematoma formation was worrisome for a third (11). The subungual myxomas involved two right thumbs $(3,11)$, two right index fingers $(8,10)$ and a right middle finger (9). A clear history of trauma associated with the onset of a lesion was reported in only one case (9). Osteolytic changes were observed on radiographs in two of the cases $(3,11)$.

In 1948, Stout (2) characterized the histological criteria for diagnosis of a myxoma as spindle shaped cells in a loose matrix of reticulin and collagen fibres; the absence of any differentiated cellular elements including chondroblasts, lipoblasts and rhabdomyoblasts; unicentric origin, growing by expansion and infiltration; and without metastasis. These features are also found in the superficial angiomyxoma.

Allen et al (4) differentiated the superficial angiomyxoma from myxoma based on the presence of a prominent capillary network and an inflammatory cell infiltrate. Occasionally, epithelial inclusions and appendage structures were also noted in superficial angiomyxomas. They (4) hypothesized that the squamous epithelial elements, basaloid buds and appendage structures, if present, were trapped during expansile growth rather than arising secondarily within the tumour.

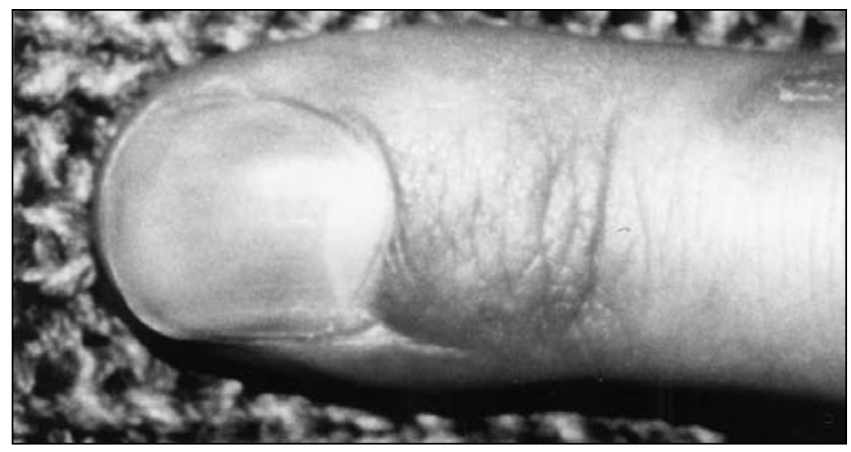

Figure 5) Dorsal postoperative views at 46 weeks showing scar at the ulnar border of the proximal nail fold - nail plate is beneath the lateral nail fold

Calonje et al (5) observed that 23\% of superficial angiomyxomas also had rounder, plumper cells with abundant eosinophilic cytoplasm and darker nuclei, in addition to the elongated stellate or bipolar fibroblastic cells.

Vascular structures were identified in micrographs of two $(8,10)$ of the five reported subungual myxomas compared with those of the superficial subungual angiomyxoma described in this report. Kaehr and Klug (8) published their findings before the introduction of the term 'superficial angiomyxoma' by Allen et al (4), and did not comment on vascularity in the histological description of the featured lesion. Gourdin and Pearon (10) remarked that the myxoma was relatively avascular. Neither of those authors commented on the presence of an inflammatory cell infiltrate. According to the diagnostic criteria employed by Allen et al (4) and Calonje et al (5), micrographs of these two lesions display evidence of vascularity, a feature that differentiates the recently labelled superficial angiomyxoma from myxoma.

Complete surgical excision was the method of treatment in all five cases. Four of the five subungual myxomas arose from beneath the nail bed, necessitating surgical elevation of this structure $(3,8,9,11)$. Rozmaryn and Schwartz (11) used a midlateral digital incision, leaving the nail fold and matrix intact to avoid scarring of the nail matrix and subsequent nail ridging. In contrast, the lesion described by Gourdin and Pearon (10), originating from the dorsal aspect of the nail matrix, was situated dorsal to the nail bed and did not require nail bed elevation for removal.

Postoperative recurrence has been reported following excision of both the myxoma and superficial angiomyxoma. Stout (2) reported a myxoma recurrence rate of $44 \%$ (12 of 27) following excision. Subsequently, Enzinger (7) and Ireland et al (6) reported reduced recurrence rates of $0 \%(0$ of 33 ) and 4\% (two of 55), respectively, following simple excision without attention to margins. Meanwhile, Allen et al (4) and Calonje et al (5) reported recurrence rates of $38 \%$ (eight of 21) and 39\% (seven of 21), respectively, for superficial angiomyxomas. Allen et al (4) reported a greater than $63 \%$ recurrence rate in lesions featuring epithelial inclusions. Four of the five subungual myxoma cases 
$(3,8,9,11)$ did not recur at follow-up between eight and 16 months after excision. Recurrence did not take place at 11 months after the operation in the present patient.

Myxoma and superficial angiomyxoma should be considered in the differential diagnosis of subungual solid masses. Re-examination of previous subungual myxoma cases may prompt reclassification of those myxomas that possess a prominent vascular pattern and notable cellular

\section{REFERENCES}

1. Virchow R. Cellular pathology as based upon physiological and pathological histology. Translated by Chance F. Philadelphia: JB Lippincott, 1863. [reprinted in New York: Dover Publications, 1971:526]

2. Stout AP. Myxoma: The tumor of primitive mesenchyme. Ann Surg 1948;127:706-19.

3. Sanusi ID. Subungual myxoma. Arch Dermatol 1982;118:612-4.

4. Allen PW, Dymock R-B, MacCormac L-B. Superficial angiomyxomas with and without epithelial components. Am J Surg Pathol 1988;12:519-30.

5. Calonje E, Guerin D, McCormick D, et al. Superficial angiomyxoma: Clinicopathologic analysis of a series of distinctive but poorly recognized cutaneous tumors with tendency for recurrence. Am J Surg Pathol 1999;23:910-7. density. To this end, an objective description of the capillary network and degree of cellularity may be of use in differentiating consistently between the lesions. Given the significant recurrence rates demonstrated by angiomyxomas, greater attention to complete excision as well as follow-up to detect recurrence is advisable in the treatment of both myxoma and superficial angiomyxoma within the nail bed.

6. Ireland DCR, Soule EH, Ivins JC. Myxoma of somatic soft tissues: A report of 58 patients, 3 with multiple tumors and fibrous dysplasia of bone. Mayo Clin Proc 1973;48:401-10.

7. Enzinger FM. Intramuscular myxoma: A review and follow-up study of 34 cases. Am J Clin Pathol 1965;43:104-13.

8. Kaehr D, Klug MS. Subungual myxoma. J Hand Surg [Am] 1986;11:73-6.

9. Winke BM, Blair WF, Benda JA. Myxomas in the fingertips. Clin Orthop 1988;237:271-4.

10. Gourdin FW, Pearon GL. Cylindrical deformity of the nail plate secondary to subungual myxoma. I Am Acad Dermatol 1996;35:846-8.

11. Rozmaryn LM, Schwartz AM. Treatment of subungual myxoma preserving the nail matrix: A case report. J Hand Surg [Am] 1998;23:178-80. 